\title{
FUNÇÃO SOCIAL DA PROPRIEDADE RURAL E A PROTEÇÃO JURÍDICA DO MEIO AMBIENTE
}

\author{
Micheli Mayumi Iwasaki*
}

\section{RESUMO}

A análise hermenêutica dominante da função social da propriedade permite constatar que a tutela jurídica da propriedade, especialmente da terra, reflete as aspirações burguesas desde o início da Modernidade. É nítida a incompatibilidade delas com a noção de Estado do Bem Estar Social, que persiste em manter a lógica de interesses desse mesmo grupo social. Assim, apresenta-se uma leitura alternativa, já defendida por alguns juristas, em que o exercício da função social da propriedade compõe uma condição da própria existência de tal direito e caracteriza uma imposição constitucional incondicional. No ordenamento jurídico pátrio a função social da propriedade está presente em vários instrumentos normativos, dentre eles a Constituição Federal da República (norma fundamental), o Estatuto da Terra, Código Civil etc. O seu conteúdo pode ser divido em três dimensões que se cumulam: econômica, humana e ambiental, sendo que cada uma delas é de extrema importância para tutelar uma série de outros direitos fundamentais decorrentes. Além disso, a partir dessa análise é possível fazer uma distinção (necessária) entre os conceitos de produtividade e o cumprimento da dimensão econômica da funcionalidade social da terra, que ainda persiste no imaginário de muitos sob falácias infundadas. Em suma, conclui-se que o primeiro seria espécie, e o segundo gênero, que por sua vez teriam repercussões diversas para proteção do meio ambiente e institutos clássicos como a desapropriação.

Palavras-chave: função social da propriedade, dimensões, classificação.

SUMÁRIO: 1 INTRODUÇÃO; 2 BREVE HISTÓRICO DA ORIGEM DO CONCEITO DE FUNÇÃO SOCIAL DA PROPRIEDADE; 3 A FUNÇÃO SOCIAL DA PROPRIEDADE RURAL NO ORDENAMENTO JURÍDICO BRASILEIRO VIGENTE; 3.1 A DIMENSÃO ECONÔMICA; 3.2 A DIMENSÃO HUMANA; 3.3 A DIMENSÃO AMBIENTAL; 4 OFALSO PARADOXO ENTRE PRODUTIVIDADE E

\footnotetext{
* Graduanda em Direito pela PUCPR. Email: michelimayumi@gmail.com
} 
RESPEITO AO MEIO AMBIENTE; 5 CONCLUSÃO; 6 REFERÊNCIAS.

\section{INTRODUÇÃO}

O senso comum dos ditos "operadores do direito", em regra, tem adotado a concepção de que a função social da propriedade constitui um elemento acessório do seu direito, o que limita a sua eficácia e aplicabilidade jurídicas. A ideologia burguesa na Modernidade difundiu a apropriação da terra como meio de produção, na sua configuração mais absoluta. E assim, com o advento do Estado do Bem Estar Social, se dá o início de uma política minimamente intervencionista no sentido de tutelar alguns direitos fundamentais, que podem ser classificados em diversas fases, e dentre eles, a função social da propriedade e o meio ambiente ecologicamente equilibrado.

\section{BREVE HISTÓRICO DA ORIGEM DO CONCEITO DE FUNÇÃO SOCIAL DA PROPRIEDADE}

O fim do século XIX e início do século XX ficaram marcados pela insurgência contra o Estado Liberal que sempre defendeu a propriedade privada absoluta. A ascensão das idéias socialistas em alguns países, a Encíclica Rerum Novarum da Igreja Católica, que embora reconhecesse a existência de um direito natural à propriedade limitava tais condições em prol da dignidade e da vida; a fundação da Organização Internacional do Trabalho, as lutas populares na América Latina ${ }^{1}$, dentre outros fatores

${ }^{1}$ Dentre as revoltas camponesas no Brasil merecem destaque neste período as Revoltas de Canudos e Contestado mencionados no capítulo anterior. Além do Brasil, o México também passava por um momento de insurgência popular no início do século XX. Sobre os episódios brasileiros ver LIBERATO, Ana Paula Gularte. Reforma agrária: direito humano fundamental. Curitiba: Juruá, 2003. 
compeliram o surgimento de um novo paradigma. ${ }^{2}$

O novo Estado capitalista foi então denominado "Interventor", do "Bem Estar Social", "Providência", ou ainda "Welfare State", que trazia consigo um rol de direitos sociais que incluíam educação, saúde, alimentação, previdência, pleno emprego e a fixação de condições mínimas de trabalho. Infelizmente, até então o Estado não teve sucesso para implementação de tais propostas, ainda que se acredite num período transicional ${ }^{3}$, mantendo a lógica de dominação burguesa com um requinte diverso de exploração das classes operárias e camponesas. Acrescenta Carlos Marés de Souza Filho ${ }^{4}$ :

Baseado na mão de obra barata, na dificuldade de acesso à terra e na exploração da miséria e do analfabetismo, o Estado do Bem Estar Social na América Latina foi implantado à força, mas ficou parecendo um arremedo mal acabado do original europeu, benefícios sociais legislados a conta gotas não chegaram nunca aos reais necessitados e destinatários.

Assim, nesse período surgem as Constituições do México (1917) e de Weimar (1919), pioneiras no emprego do instituto da função social da propriedade. A mexicana foi a mais audaz no avanço das políticas sociais, e principalmente da propriedade da terra, ainda em vigência hodiernamente, enquanto a segunda teve sua história bastante curta.

A Constituição do México é muito contundente ao vetar a concepção de que a propriedade da terra e águas seja um direito natural. Quanto à intervenção na propriedade distingue duas possibilidades: da desapropriação mediante indenização, e o não reconhecimento em relação à propriedade das áreas que descumpram os deveres mínimos relativos ao seu exercício, e assim autoriza o Estado a regular a utilização adequada dos elementos naturais da riqueza. Além disso, restringe várias questões

${ }^{2}$ SOUZA FILHO, Carlos Frederico Marés de. A função social da terra. Porto Alegre: Fabris, 2003, p. 81-86.

${ }^{3}$ SANTOS, Boaventura de Sousa. A crítica da razão indolente: contra o desperdício da experiência. São Paulo: Cortez, 2000-2001. v. 1.

${ }^{4}$ SOUZA FILHO, op. cit., p. 83. 
referentes à propriedade rural quanto a sua extensão, enumerando várias proibições, e, antes mesmo da fundação da OIT (Organização Internacional do Trabalho), já regulamentava vários direitos trabalhistas como a limitação de oito horas por jornada de trabalho, horas extras, descanso semanal remunerado, férias, forma de pagamento do salário, igualdade de gênero na remuneração, a impenhorabilidade, licença maternidade, participação nos lucros, dentre outros, enquanto que muitos destes direitos somente foram finalmente conquistados no Brasil com a Constituição da República de $1988 .^{5}$

No ano seguinte, em 1918, era promulgada a Constituição Soviética, também denominada Declaração dos Direitos do Povo Trabalhador e Explorado que, já no seu primeiro artigo, abolia a propriedade privada da terra. Posteriormente, em 1919 veio a público a Constituição de Weimar e a restrição ao direito absoluto de propriedade denominada "função social da propriedade", ao passo que em terras brasileiras, o Código Civil de 1916 literalmente traduzia o espírito eminentemente liberal do Código Napoleônico. ${ }^{6}$ Por sua vez, a ideologia do Código Civil Francês, de cunho altamente individualista, reproduzido no Brasil, pode ser examinado no seu artigo 344, regulando a propriedade como "o direito de gozar e dispor das coisas da maneira mais absoluta, desde que delas não se faça uso proibido pelas leis e regulamentos". ${ }^{7}$

Outros países da América Latina também regulamentaram a função social da propriedade, na maioria com outras terminologias, mas sempre com o cuidado de se proteger um piso mínimo do bem-estar coletivo.

No Brasil, as iniciativas legislativas aconteceram de forma um tanto quanto desorganizada, leis como a do Tombamento e o próprio Estatuto da Terra se confundem com os períodos de ausência de democracia, e pouco se avançava nas políticas tão reivindicadas pelos movimentos populares. Ao contrário de países como a

${ }^{5}$ Ibidem, p. 94-95.

${ }^{6}$ Ibidem, loc. cit.

${ }^{7}$ ARAÚJO, Telma de. A propriedade e sua função social. In: LARANJEIRA, Raymundo. Direito agrário brasileiro: em homenagem à memória de Fernando Pereira Sodero. São Paulo: LTr, 2000. p.156. 
Bolívia, México e a Colômbia, a legislação nacional era muito tímida para enfrentar a estrutura fundiária já arraigada no país desde os períodos de colonização, embora tivesse algumas políticas em princípio humanizadoras para o campo. A Lei do Tombamento $^{8}$, impulsionada pela Semana de Arte Moderna de São Paulo, em 1922, é a primeira fonte normativa a proteger um direito coletivo, especificamente os bens de propriedade imaterial, de natureza cultural, histórica e artística.

Após, a Constituição de 1946 foi a primeira a adotar a função social da propriedade, nas palavras de Gustavo Tepedino e Anderson Schreiber, como "produto de uma postura intervencionista e assistencialista adotada pelo Estado brasileiro". Similar à Constituição de Weimar, trazia o artigo 147: “O uso da propriedade será condicionado ao bem estar social. A lei poderá, com observância do disposto no art. $141, \S 16$, promover a justa distribuição da propriedade com igual oportunidade para todos”. Já a Constituição de 1967 promoveu o instituto à categoria de princípio da ordem econômica e social com a seguinte redação: “A ordem econômica e social tem por fim realizar o desenvolvimento nacional e a justiça social, com base nos seguintes princípios: (...) III - função social da propriedade". 9

Em 1964, o Estatuto da Terra ${ }^{10}$ regula o conteúdo do termo "função social da propriedade", que depois é ampliado na Constituição de 1988 com status de direito fundamental, conforme se verá no próximo tópico, ambas em vigor atualmente, assim como a Lei do Tombamento anteriormente mencionada.

\footnotetext{
${ }^{8}$ Decreto-Lei 25/1937.
}

${ }^{9}$ TEPEDINO, Gustavo; SCHREIBER, Anderson. Função social da propriedade e legalidade constitucional. Revista Direito, Estado e Sociedade, v. 9, n. 17, p. 41-57, ago./dez. 2000. 


\section{A FUNÇÃO SOCIAL DA PROPRIEDADE RURAL NO ORDENAMENTO JURÍDICO BRASILEIRO VIGENTE}

O conceito de função social não é trazido expressamente pela Carta Maior, mas pode ser analisado separada e sucessivamente, caracterizado, em suma, por 'função' por aquilo que se contrapõe a uma estrutura previamente estabelecida, qual seja, dos interesses do proprietário, admitido em três aspectos distintos: "privação de determinadas faculdades; a criação de um complexo de condições para que o proprietário possa exercer seus poderes; e a obrigação de exercer certos direitos elementares do domínio." Por 'social' constata-se um sentido ambíguo, que amplia o não-individualístico como "critério de avaliação de situações jurídicas ligadas ao desenvolvimento de determinadas atividades econômicas, para maior integração do indivíduo na coletividade", que assume um "caráter elástico" e que leva a indeterminação exata do seu conceito. ${ }^{11}$

A Constituição Federal da República de 1988 positivou alguns elementos mínimos que possibilitam e limitam o exercício do direito de propriedade, ao dispor no título dos direitos e garantias fundamentais, in verbis:

Art. $5^{\circ}$ Todos são iguais perante a lei, sem distinção de qualquer natureza, garantindo-se aos brasileiros e aos estrangeiros residentes no País a inviolabilidade do direito à vida, à liberdade, à segurança e à propriedade, nos termos seguintes:

$[\ldots]$

XXII - é garantido o direito de propriedade

XXIII - a propriedade atenderá a sua função social.

Tal previsão constitucional deixou a cargo da hermenêutica a sua aplicação, admitindo vertentes diversas. O entendimento dominante admite que o direito de propriedade reste assegurado mesmo que não se cumpra a sua função social, ou seja,

\footnotetext{
${ }^{10}$ Lei $n^{\circ} 4.504$ de 30 de novembro de 1964.

${ }^{11}$ GOMES, Orlando; FACHIN, Luiz Edson. Direitos reais. 19. ed. Rio de Janeiro: Forense, 2004, p. 123-125.
} 
nesta leitura configuraria um direito e garantia fundamental da coletividade de ordem facultativa. É inegável a incoerência dessa interpretação.

Na análise do jurista Luiz Edson Fachin, a função social da propriedade causa justificativa da própria existência da propriedade ${ }^{12}$, que pode ser admitida por meio de uma simples leitura sistemática do artigo $5^{\circ}$. Uma vez que se encontra sob o título dos direitos e garantias fundamentais, não restam dúvidas que são irrenunciáveis, intransferíveis e compõem a base do Estado democrático de direito. Assim, a propriedade deve obrigatoriamente atender à sua função social, sendo que o seu descumprimento motiva a inexistência do direito. Em outras palavras, o direito de propriedade da terra só poderia ser garantido e tutelado pelo Estado quando a mesma cumprir sua função social.

No mesmo sentido ainda afirma Marés de Souza ${ }^{13}$ :

É tão insistente a Constituição que se pode dizer, fazendo eco ao Professor colombiano Guillermo Benavides Melo, que no Brasil, pós 1988 a propriedade que não cumpre sua função social não está protegida, ou, simplesmente, propriedade não é. Na realidade quem cumpre uma função social não é a propriedade, que é um conceito, uma abstração, mas a terra, mesmo quando não alterada antropicamente, e a ação humana ao intervir na terra, independentemente do título de propriedade que o Direito ou o Estado lhe outorgue. Por isso a função social é relativa ao bem e ao seu uso, e não ao direito. A desfunção ou violação se dá quando há um uso humano, seja pelo proprietário legitimado pelo sistema, seja por ocupante não legitimado. Embora esta concepção esteja clara por todo texto constitucional, a leitura que tem feito a oligarquia omite o conjunto para reafirmar o antigo e ultrapassado conceito de propriedade privada absoluta. A interpretação, assim, tem sido contra lei.

Rafael Egídio Leal e Silva pontua a condição de cláusula pétrea e de aplicação imediata da funcionalidade social, sendo assim um "dever-coletivo" em que a propriedade só passa a estar garantida com o cumprimento daquela. Segue, portanto, com a seguinte afirmação:

12 FACHIN, Luiz Edson. Das províncias do direito privado à causa justificativa da propriedade. In: LARANJEIRA, Raymundo. Direito agrário brasileiro: em homenagem à memória de Fernando Pereira Sodero. São Paulo: LTr, 2000. p. 121-131. 
O direito a propriedade não foi restringido, aliás, continua próprio do indivíduo. A função social também passou a ser um fundamento básico. $O$ interesse individual deve ser submetido ao bem-estar geral. A função social não significa a limitação do direito de propriedade, mas, como diz Rosalinda Pereira, constitui 'poder-dever do proprietário, ou seja, dever positivo do proprietário, que é de dar à propriedade destino determinado, dar-lhe uma função determinada'. ${ }^{14}$

Adiante, no título da ordem econômica e financeira, capítulo da política agrícola e fundiária e da reforma agrária, determina a Carta Magna:

Art. 186 A função social é cumprida quando a propriedade rural atende, simultaneamente, segundo critérios e graus de exigência estabelecidos em lei, aos seguintes requisitos:

I - aproveitamento racional e adequado;

II - utilização adequada dos recursos naturais disponíveis e preservação do meio ambiente;

III - observância das disposições que regulamentam as relações de trabalho;

IV - exploração que favoreça o bem-estar dos proprietários e trabalhadores.

É possível afirmar que a propriedade rural possui assim três dimensões ${ }^{15}$ que se complementam: econômico, humano e ambiental. Deste modo, para cumprir sua função social, a propriedade deve atender as três dimensões de forma cumulativa. $O$ Estatuto da Terra, também aplicável à propriedade rural por ser norma específica, de forma similar, também estabelece os três elementos. Senão veja-se:

${ }^{13}$ SOUZA FILHO, op. cit., p. 116.

14 LEAL E SILVA, Rafael Egídio. Função social da propriedade rural: aspectos constitucionais e sociológicos. Revista de Direito Constitucional e Internacional, São Paulo, a. 9, n. 37, p. 259-260, out./dez. 2001.

15 Roberto Wagner Marquesi sustenta a existência de quatro 'fatores': econômico, econômico-ambiental, social e humano-social (MARQUESI, R. W. : 2001, p. 98-108). A preferência pela terminologia adotada se funda no entendimento de que as três dimensões mencionadas compreendem os quatro requisitos, parecendo contraditório separar a questão do trabalho e do bem estar dos trabalhadores e proprietário. O 'fator' humano-social e o 'social' integram a dimensão humana da propriedade, que teria como conteúdo qualquer violação a direito fundamental. Ainda, para 'social' seria necessário distinguir a espécie e o gênero (função social). Já a utilização de 'econômicoambiental' determina um caráter estritamente pecuniário às espécies de meio ambiente. $\mathrm{O}$ autor trata desta forma porque parte do pressuposto que propriedade produtiva descumpridora da função social é imune à desapropriação, da qual se discorda como se verá adiante. 
Art. $2^{\circ}$ É assegurada a todos a oportunidade de acesso à propriedade da terra, condicionada pela sua função social, na forma prevista nesta Lei.

$\S 1^{\circ}$ A propriedade da terra desempenha integralmente a sua função social quando, simultaneamente:

a) favorece o bem-estar dos proprietários e dos trabalhadores que nela labutam, assim como de suas famílias;

b) mantém níveis satisfatórios de produtividade;

c) assegura a conservação dos recursos naturais;

d) observa as disposições legais que regulam as justas relações de trabalho entre os que a possuem e a cultivem.

\subsection{A DIMENSÃO ECONÔMICA}

O "aproveitamento racional e adequado" não se equipara ao conceito de produtividade, embora guardem alguma semelhança. Este, determinado pela lei infraconstitucional, é quantitativo e calculável, sendo medido através do GUT (Grau de Utilidade da Terra). ${ }^{16}$ Já o primeiro foi conceituado pela lei 8.629 , de 25 de fevereiro de 1993, de forma bastante taxativa:

Artigo $8^{\circ}$ - Ter-se-á como racional e adequado o aproveitamento de imóvel rural, quando esteja oficialmente destinado à execução de atividades de pesquisa e experimentação que objetivem o avanço tecnológico da agricultura.

$[\ldots]$

Art. $9[\ldots]$

Considera-se racional e adequado o aproveitamento que atinja os graus de utilização da terra e de eficiência na exploração especificados nos $\S \S 1^{\circ}$ a $7^{\circ}$ do artigo $6^{\circ}$ desta Lei.

Nota-se que o legislador infraconstitucional conceitua o "aproveitamento racional e adequado" da propriedade, previsto na Constituição da República, como se fosse restrita à "produtividade", o que não procede, visto que esta se encontra diretamente ligada às demandas da economia de mercado. Parece precário afirmar que

\footnotetext{
${ }^{16}$ O GUT é calculado por perícia técnica levando-se em conta inúmeros fatores na área.
} 
uma área sem destinação estritamente econômica não prevista nas exceções taxativas, destituída de qualquer produção nos termos da lei ${ }^{17}$, deixa de cumprir a sua função social por não aproveitar a propriedade de forma racional e adequada. Portanto, é possível afirmar que a noção de aproveitamento (gênero) e a produtividade (espécie), sendo que a primeira deve ser a aplicada.

Ainda, sobre esta dimensão há que se destacar que os índices estão completamente defasados. Os cálculos são feitos com base no que se produzia por volta da década de 70, que não condiz com os níveis de produtividade atuais. A utilização intensiva da terra por meio dos fertilizantes e o melhoramento das sementes pós-Revolução Verde aumentou drasticamente tais indicadores. No entanto, não é do interesse político que estes números sejam atualizados, motivo pelo qual permanecem tão defasados há tanto tempo. Por outro lado, a não imposição de níveis maiores de produtividade também autorizam que a utilização da terra seja menos intensa, e a intervenção antrópica reduzida.

\subsection{A DIMENSÃO HUMANA}

A segunda dimensão tem o viés humano, que visa garantir a proteção dos direitos dos trabalhadores e trabalhadoras rurais. Além disso, preocupa-se com o seu bem-estar, ou seja, não basta respeitar as leis trabalhistas, também é inadmissível a submissão das pessoas a trabalhos que põe em risco a sua saúde e a vida, assim como do próprio empregador. A garantia do bem-estar compreende o atendimento às necessidades básicas, toda a segurança do proprietário e seus empregados, seja na utilização de agrotóxicos, atividade de carvoarias, mineração, entre outras, além de

\footnotetext{
${ }^{17}$ Artigo 10 - "Para efeito do que dispõe esta lei, consideram-se não aproveitáveis: $[\ldots]$

IV - as áreas de efetiva preservação permanente e demais áreas protegidas por legislação relativa à conservação dos recursos naturais e à preservação do meio ambiente".
} 
não causar tensões sociais e/ou conflitos. ${ }^{18}$ Englobam ainda a intolerância à exploração do trabalho escravo, infantil e o regime de servidão, incompatíveis com uma sociedade democrática. Neste caso, o Estatuto da Terra, embora utilize texto dessemelhante ao da Constituição Federal, não implica em divergência semântica quanto ao seu conteúdo.

\subsection{A DIMENSÃO AMBIENTAL}

A utilização adequada dos recursos naturais disponíveis e a preservação do meio ambiente compõem a terceira dimensão da função social da propriedade. Nesse ponto, o Estatuto da Terra se restringe à "conservação dos recursos naturais".

Basicamente, a diferença entre a norma constitucional e a especial é que por recurso natural entende-se tudo que pode ser transformado em proveito do homem, e o verbo conservação denota a boa utilização dos mesmos. Já a preservação impõe a não utilização do meio ambiente, o qual engloba tudo o que pertence à natureza, sejam estes bens materiais ou imateriais.

Assim, é possível afirmar que meio ambiente é um conceito mais amplo que recursos naturais, sendo este uma espécie daquele. A doutrina não deixou de apontar a redundância do termo, uma vez que meio significa 'que envolve' e ambiente 'que rodeia'. De qualquer forma, qualquer vício lingüístico na terminologia não traz grandes consequiências, sendo de caráter meramente formal. O conceito de meio ambiente a priori foi definido pela Lei de Política Nacional do Meio Ambiente como “o conjunto de condições, leis, influências e interações de ordem física, química e biológica, que permite, abriga e rege a vida em todas as suas formas". ${ }^{19}$ Tal dispositivo não trouxe grandes avanços na tutela ambiental uma vez que não se tratava

\footnotetext{
${ }^{18}$ ARAÚJO, op. cit., p. 165.

${ }^{19}$ Artigo $3^{\circ}$, I da Lei 6.938 de 31 de agosto de 1981.
} 
de um conceito jurídico, mas sim da Ecologia. ${ }^{20}$

Posteriormente, a Constituição da República de 1988 solucionou a controvérsia, trazendo em seu artigo 225 a seguinte redação:

Art. 225. Todos têm direito ao meio ambiente ecologicamente equilibrado, bem de uso comum do povo e essencial à sadia qualidade de vida, impondo-se ao Poder Público e à coletividade o dever de defendê-lo e preservá-lo para as presentes e futuras gerações.

Deste modo, a Carta Magna conferiu ao meio ambiente status de direito transindividual, ou seja, foi incluído na categoria de direitos difusos.

A doutrina ainda tipifica espécies do meio ambiente, quais sejam: natural, cultural, trabalho e urbano. Obviamente, todos estão incluídos na dimensão ambiental da função social, sendo que a espécie natural sempre está vinculada à propriedade rural e por isso será abordado com maior destaque.

Inclui-se, ainda, nesta dimensão da função social, a utilização adequada dos recursos naturais que deve ser verificada mediante a exploração que respeita a vocação natural da terra, mantendo também, o potencial produtivo da propriedade. ${ }^{21}$

Em um primeiro momento, parece haver um paradoxo em se garantir uma tutela coletiva sobre um direito quase que exclusivamente individual, no caso, em relação à propriedade. Ambos, embora sejam antagônicos, devem coexistir de forma a proteger não só os interesses do indivíduo proprietário, mas também da coletividade. Em havendo o conflito de interesses, deve prevalecer o que Canotilho denomina “direito subjetivo público", ou seja, o direito supra-individual. ${ }^{22}$

${ }^{20}$ MACHADO, Paulo Affonso Leme. Direito ambiental brasileiro. 14. ed. rev. atual. ampl. São Paulo: Malheiros, 2006, p. 146-147.

${ }^{21}$ ARAÚJO, op. cit., p.165.

${ }^{22}$ CANOTILHO, J. J. Gomes. Protecção do ambiente e direito de propriedade: crítica de jurisprudência ambiental. Coimbra: Coimbra, 1995. 


\section{O FALSO PARADOXO ENTRE PRODUTIVIDADE E RESPEITO AO MEIO AMBIENTE}

A tutela ao meio ambiente é bastante recente e muitos são os sofismas reproduzidos no que tange à sua proteção. Dentre elas, a mais arraigada no pensamento de grande parte dos operadores do direito é que a produtividade, por si só, contempla o cumprimento da função social da propriedade. No entanto, não há como proceder tal afirmativa.

Conforme anteriormente tratado, a Carta Magna de 1988 estabelece expressamente que todas as dimensões devem ser respeitadas cumulativamente. Historicamente se admitiu que a função social fosse sinônima de produtividade, a qual seria uma espécie do "aproveitamento racional e adequado".

O Estatuto da Terra de 1964 quando se refere à conservação dos recursos naturais já antecipou uma condição para tutela ambiental, permitindo uma intervenção do poder público na propriedade privada admitida até então de forma absoluta e total. Assim, não há elementos que justifiquem a utilização de um único critério, o econômico, de forma tão simplista e que contraria a norma constitucional para definir o cumprimento ou não da sua função social.

Ainda, há que se ressaltar que a mera utilização dentro dos limites legais não bastam para sua caracterização. É imprescindível que o uso esteja conforme as regras gerais de preservação do meio ambiente. Na obra "Protecção do ambiente e direito de propriedade", Canotilho apresenta um caso que se enquadra perfeitamente a presente reflexão, que ele mesmo espera ser um leading case para jurisprudência ambientalista portuguesa.

Neste episódio, o Ministério Público ingressou com ação ordinária, após o sucesso no provimento de uma ação cautelar, contra os proprietários de uma área denominada "Quinta do Taipal", pertencente a Comarca de Montemor-o-Velho, uma vez que os mesmos possuíam uma área alagada de 50 hectares onde pretendiam fazer o cultivo de arroz. Ocorre que esta área, tecnicamente classificada como úmida, era o 
habitat natural de muitos animais, alguns inclusive ameaçados de extinção, e de uma biodiversidade muito rica, onde seria necessário fazer o enxugo para a produção.

Embora legalmente não houvesse qualquer proibição legal de que os proprietários utilizassem a área, em quase todas as instâncias recursais o Ministério Público foi vitorioso. Os réus alegavam ofensa a livre iniciativa privada, a expropriação por não poderem fruir de sua propriedade, dentre muitos outros argumentos que não foram acatados, exceto na última instância. No Superior Tribunal de Justiça português houve o reconhecimento que a restrição ao direito de propriedade implicaria em uma servidão que somente à Administração Pública cabia suportar, revogando o decidido nas instâncias anteriores e com a previsão de se criar uma reserva para as aves. ${ }^{23}$

Este é um exemplo em que a produtividade não pode ceder lugar a proteção ambiental. Em momento algum havia proibição legal de que os proprietários plantassem arroz, mas, por opção do intérprete, se entendeu que o direito subjetivo público deveria prevalecer sobre o individual. A decisão foi embasada na autoaplicação de dispositivo constitucional que afirma o meio ambiente como um direito difuso, onde todos têm o dever de preservá-lo. Tal dever foi entendido então como uma obrigação que acompanha a propriedade, sendo uma limitação aos poderes de uso, gozo e fruição da terra.

A confusão feita na doutrina e na jurisprudência entre produtividade e a função social tem como fundamento o artigo 185 da Constituição da República que afirma, expressamente, a impossibilidade da desapropriação das terras produtivas, deixando à legislação infraconstitucional a responsabilidade de regulamentar o "tratamento especial". 24

${ }^{23}$ CANOTILHO, op. cit.

${ }^{24}$ Art. 185. "São insuscetíveis de desapropriação para fins de reforma agrária:

I - a pequena e média propriedade rural, assim definida em lei, desde que seu proprietário não possua outra;

II - a propriedade produtiva.

Parágrafo único. A lei garantirá tratamento especial à propriedade produtiva e fixará normas 
Celso Antônio Bandeira de Mello é um dos autores que se filia a essa interpretação, afirmando que "poderá haver propriedade descumpridora da função social, mas livre desta modalidade expropriatória, por ser produtiva ou por se qualificar como média ou pequena, se seu proprietário não tiver outra" ${ }^{25}$ É certo que este conflito aparente de normas foi propositado, pensado já na constituinte como uma forma de ofuscar o brilho dos novos direitos, reconhecidos na norma fundamental.

A interpretação feita de forma sistemática levaria a conclusão diversa da dominante na doutrina e nos tribunais. Conforme ressalta Marés de Souza Filho, a leitura deve ser feita conjuntamente com os artigos $5^{\circ}$, incisos XXII e XXIII e Título VII, artigo 170, incisos I e II, os quais atrelam a propriedade ao cumprimento de sua função social. Neste sentido, o entendimento mais adequado ao artigo 185 da Constituição Federal da República é de que a propriedade produtiva e que cumpre a sua função social no todo é insuscetível de desapropriação, não se resumindo ao critério econômico, mas sim a todas as suas dimensões. Veja-se:

A terra está destinada a dar frutos para todas as gerações, repetindo a produção de alimentos e outros bens, permanentemente. O seu esgotamento pode dar lucro imediato, mas liquida sua produtividade, quer dizer a rentabilidade de um ano, o lucro do ano, pode ser prejuízo no ano seguinte. E prejuízo aqui não apenas financeiro, mas traduzido em desertificação, que quer dizer fome, miséria, desabastecimento. É demasiado egoísmo imaginar que a produtividade como conceito constitucional queira dizer o lucro individual e imediato. Ao contrário, produtividade quer dizer capacidade de produção reiterada, o que significa, pelo menos, a conservação do solo e a proteção da natureza, isto é, o respeito ao que a Constituição chamou de meio ambiente ecologicamente equilibrado. ${ }^{26}$

No mesmo sentido, Guilherme José Purvin de Figueiredo, analisando a decisão final do Superior Tribunal de Justiça de Portugal descrita na obra de Canotilho, critica o direito a indenização pelo Poder Público fundada na cessação de

para o cumprimento dos requisitos relativos a sua função social".

${ }^{25}$ MELLO, Celso Antônio Bandeira de. Curso de direito administrativo. 18. ed. rev. atual. São Paulo: Malheiros, 2005, p. 801.

${ }^{26}$ SOUZA FILHO, Carlos Frederico Marés. Direito agrário e meio ambiente. In: LARANJEIRA, Raymundo (org.). Direito agrário brasileiro: em homenagem à memória de Fernando Pereira Sodero. São Paulo: LTr, 2000. p. 516-517. 
um dano ambiental. Embora naquele país não haja previsão constitucional expressa da função social da propriedade, a adoção desse entendimento levaria a conclusão de que ao proprietário é garantido um "direito adquirido de poluir" que somente seria afastado por uma indenização. ${ }^{27}$

Outros autores ainda fazem esta distinção. Roxana Cardoso Brasileiro Borges, sustenta que a produtividade e o atendimento aos requisitos da função social seriam critérios cumulativos e não excludentes. A autora critica a doutrina, utilizando uma citação de Leandro Paulsen, para quem, os dispositivos do artigo 185 denotam condições negativas, ou seja, basta a sua configuração para que a propriedade seja insuscetível de desapropriação. Prossegue ainda fazendo conveniente citação de Jacques Távora Alfonsin:

Desde a entrada em vigor da Constituição Federal de 1988, o debate sobre a conveniência e a oportunidade da reforma agrária para o País parece ter dado mais atenção aos objetivos do que aos sujeitos dessa forma de desenvolvimento. [...] O problema maior [...] se situa no fato de que, ao poder de exclusão 'contra todos' do proprietário, não corresponde, em nível de mercado, nenhum poder da sociedade contra ele. Ao poder de apropriação capitalista de acumular sem limites, em favor de um, contra o qual não existe qualquer tipo de controle jurídico eficaz, não corresponde um poder prévio de proteção, em favor de todos, do mau uso ou do uso abusivo que o proprietário poderá fazer da coisa adquirida. [...] Há um reducionismo, relacionado a interpretação do art. 185, II, da Constituição Federal, que deixa imune de desapropriação a chamada propriedade produtiva. Parece ter havido precipitação em confundi-la, sem mais, com a propriedade que cumpre sua função social, de acordo com o art. 186 da mesma Carta.

Assim, Roxana Cardoso Brasileiro Borges conclui que o conflito aparente de normas sugere uma antinomia real que não pode ser solucionada pelos critérios de hierarquia, cronologia e especificidade, mas pelos métodos da interpretação sistemática, da exclusão das normas conflitantes e verificação da vertente dominante no texto constitucional, e da manutenção de ambas com o pressuposto de que a propriedade produtiva atende aos requisitos do artigo 186. Nos três métodos, fundamentados na filosofia jurídica de Norberto Bobbio, fica nítida a vontade da Carta

27 FIGUEIREDO, Guilherme José Purvin de. A propriedade no direito ambiental: a dimensão ambiental da função social da propriedade. Rio de Janeiro: ADCOAS, 2004, p. 100. 
Magna onde os direitos e garantias ao bem estar comum, meio ambiente ecologicamente equilibrado, proteção do trabalho, dentre tantos outros permeiam todo o ordenamento jurídico. ${ }^{28}$

Portanto, fica evidente que a produtividade por si só não implica em respeito ao meio ambiente, ambas devem coexistir, e em havendo conflito, prevalece o direito coletivo lato sensu ao individual para os casos de intervenção do Estado na propriedade.

\section{CONCLUSÃO}

A propriedade da terra, principalmente no que tange à questão agrária, ainda constitui um forte instrumento de exclusão social e de manutenção de privilégios. Nesse contexto, a Constituição da República positivou a função social da propriedade como um imperativo indispensável para que fosse possível uma re-estruturação da distribuição fundiária, e, principalmente permitisse uma política eficaz para reforma agrária.

No entanto, os discursos jurídicos do senso comum dos juristas e principalmente a aplicação majoritariamente conservadora dos tribunais faz da função social da propriedade uma previsão ineficaz em detrimento do interesse econômico de grileiros e latifundiários. Por esse motivo há que se dissecar o conteúdo da função social da propriedade, suas características e classificações para que não se continue a perpetuar a falácia de que a propriedade produtiva é insuscetível de desapropriação. Além disso, há que se conceber que outros limites e restrições podem ser impostos em razão da função social para tutelar direitos coletivos inerentes à propriedade individual da terra, nos quais o interesse da sociedade deve ser contemplado em caso de conflito.

${ }^{28}$ BORGES, Roxana Cardoso Brasileiro. Função ambiental da propriedade rural. São Paulo: LTr, 1999, p. 189-202. 


\section{REFERÊNCIAS}

ARAÚJO, Telma de. A propriedade e sua função social. In: LARANJEIRA, Raymundo. Direito agrário brasileiro: em homenagem à memória de Fernando Pereira Sodero. São Paulo: LTr, 2000.

BORGES, Roxana Cardoso Brasileiro. Função ambiental da propriedade rural. São Paulo: LTr, 1999.

CANOTILHO, J. J. Gomes. Protecção do ambiente e direito de propriedade: crítica de jurisprudência ambiental. Coimbra: Coimbra, 1995.

FACHIN, Luiz Edson. Das províncias do direito privado à causa justificativa da propriedade. In: LARANJEIRA, Raymundo. Direito agrário brasileiro: em homenagem à memória de Fernando Pereira Sodero. São Paulo: LTr, 2000. p. 121131.

FIGUEIREDO, Guilherme José Purvin de. A propriedade no direito ambiental: a dimensão ambiental da função social da propriedade. Rio de Janeiro: ADCOAS, 2004.

GOMES, Orlando; FACHIN, Luiz Edson. Direitos reais. 19. ed. Rio de Janeiro: Forense, 2004.

LEAL E SILVA, Rafael Egídio. Função social da propriedade rural: aspectos constitucionais e sociológicos. Revista de Direito Constitucional e Internacional, São Paulo, a. 9, n. 37, p. 259-260, out./dez. 2001.

LIBERATO, Ana Paula Gularte. Reforma agrária: direito humano fundamental. Curitiba: Juruá, 2003.

MACHADO, Paulo Affonso Leme. Direito ambiental brasileiro. 14. ed. rev. atual. ampl. São Paulo: Malheiros, 2006.

MARQUESI, R. W. : 2001, p. 98-108

MELLO, Celso Antônio Bandeira de. Curso de direito administrativo. 18. ed. rev. atual. São Paulo: Malheiros, 2005.

SANTOS, Boaventura de Sousa. A crítica da razão indolente: contra o desperdício da experiência. São Paulo: Cortez, 2000-2001. v. 1.

MARÉS SOUZA FILHO, Carlos Frederico. Direito agrário e meio ambiente. In: LARANJEIRA, Raymundo (org.). Direito agrário brasileiro: em homenagem à memória de Fernando Pereira Sodero. São Paulo: LTr, 2000.

. A função social da terra. Porto Alegre: Fabris, 2003. 
Revista Eletrônica do CEJUR, Curitiba-PR, a. 2, v. 1, n. 2, ago./dez. 2007

TEPEDINO, Gustavo; SCHREIBER, Anderson. Função social da propriedade e legalidade constitucional. Revista Direito, Estado e Sociedade, v. 9, n. 17, p. 41-57, ago./dez. 2000. 